\title{
Supplementary Private Health Insurance in Selected Countries: Lessons for EU Governments?
}

\author{
SEBASTIAN GECHERT
}

CESIFO WORKING PAPER No. 2739

CATEgory 3: SOCIAL PRotection

August 2009

Presented At CESifo Venice Summer Institute, July 2009

\footnotetext{
An electronic version of the paper may be downloaded

- from the SSRN website: www.SSRN.com

- from the RePEc website: - from the CESifo website: 


\title{
Supplementary Private Health Insurance in Selected Countries: Lessons for EU Governments?
}

\begin{abstract}
A famous idea to maintain affordable health expenditures is to cut back statutory health insurance (SHI) to a basic insurance and to introduce supplementary private health insurance (PHI), permitted to cover the remaining benefits and to apply managed care mechanisms. The measure is supposed to lower public health expenditures and to enhance cost efficiency and quality of service. To test these reasonings, the paper draws empirical evidence from the health systems of Australia, Canada and Switzerland. PHI fails to meet the claims in these countries, since it performs worse than SHI concerning cost development and cannot be expected to improve quality. Cream skimming and adverse selection arise instead. Therefore, regulations and incentives are necessary, but they might counteract the aim of lowering public health expenditures.
\end{abstract}

JEL Code: H51, G22, I11, I18, L10.

Keywords: private health insurance, supplementary, country survey.

\author{
Sebastian Gechert \\ Chemnitz University of Technology \\ Department of Economics \& BA \\ Thüringer Weg 7 \\ 09126 Chemnitz \\ Germany \\ gechert@wirtschaft.tu-chemnitz.de
}

First Version: March 30, 2009

This Version: July 24, 2009

Financial support by CESifo is gratefully acknowledged. I would like to thank Ingmar Kumpmann of Halle Institute for Economic Research, Pia Weiß of Nottingham Business School and the participants of the CESifo Venice Summer Institute 2009 for their helpful comments. Of course, they bear no responsibility for any mistakes. 


\section{Introduction}

Privatizing social security benefits has been a popular measure in EU countries over recent years. This is particularly the case for pension systems but also concerns national health financing systems. According to the European Commission (2005, 2008), enforcing private health insurance (PHI) seems to be an appropriate method in order to enable a rational use of health resources and to maintain affordable health expenditures. Following this rationale, a promising implementation might be to introduce a basic, statutory health insurance (SHI), supplemented by voluntary PHI covering additional benefits. Since this is actually not completely new for most of European's mixed-financed health systems (Mossialos \& Thomson 2002b), modification refers to the extend to which the basic system is responsible: In comparison to the status quo SHI - either financed by taxes or contributionsprovides significantly fewer benefits, leaving a broader field for the supplementary market with private competition-based solutions.

What are the concrete properties of the supplementary PHI scheme? Following a popular definition by OECD (2004), supplementary PHI must not cover claims already covered by basic insurance. Taking this limit into account, the extend of coverage has to be negotiated by insurer and insuree. Health services neither covered by SHI nor PHI have to be payed out of pocket (OOP). Furthermore, private insurers are permitted to use managed care mechanisms, such as selective contracting with health service providers. The approach promises several advantages. Two of them are mentioned frequently: ${ }^{1}$

1. The broadening of the market for supplementary PHI and the free conditions for contracting should comply with intense competition-both among insurers and among health service providers - leading to increased cost efficiency and quality.

2. Reducing benefits of SHI should lower the financial burden of the public system.

This paper relates to the empirical-based literature on public and private health care markets in general. ${ }^{2}$ It surveys selected countries regarding the points listed above, stressing point \#1. Main questions of this paper are: Do PHI market outcomes lead to higher cost efficiency and higher quality of service in the private sector compared to the public sector? What are the impacts of supplementary

\footnotetext{
${ }^{1}$ See for example Goldman (1995); Glied (2000); Cutler et al. (2000); Mays et al. (2004); Pati et al. (2005).

${ }^{2}$ For examples of recent literature surveying private health care markets in multiple countries, see in particular OECD (2004); Colombo \& Tapay (2004); Mossialos \& Thomson (2002a,b); Greß (2006); Paolucci et al. (2007); Tuohy et al. (2004); Leu et al. (2008).
} 
PHI markets on public health expenditures? And finally: What are the lessons from this survey for EU countries?

The methods applied are the following: First step is to select appropriate countries and to briefly describe their health system. The paper then follows a structure, conduct and performance (SCP) framework (Scherer \& Ross 1990). However, $\mathrm{SCP}$ is not applied tightly, as to deduct performance straight from structure, but rather by emphasizing conduct. Since health care markets concern public interests and have special characteristics, analysis of structure particularly stresses governmental influences. The SCP approach has already been applied to several health insurance markets. A recent study by Hammer et al. (2008) uses SCP in order to analyze the Swiss health market, but focus on SHI. Mossialos \& Thomson (2002a) apply SCP to PHI markets in European Countries, but do not refer to systems that fit the model described above. Furthermore, their study on performance lacks a comparison of costs. My paper measures performance of PHI in terms of development of costs compared to SHI using macro-data of OECD Health Data 2009 and related national data sources. More precisely, I refer to total expenditures on health and management expenditures. In order to identify performance in terms of health service quality and equity concerns, the paper refers to surveys in recent literature.

\section{Selecting appropriate countries}

As one purpose of this paper is to deduce lessons for EU governments, the countries to be surveyed should resemble EU countries concerning standard of living (expressed by GDP/capita) and life expectancy. A significant percentage of population should hold supplementary PHI and a significant share of total expenditures on health (TEH) should be claimed by the private sector. Which countries fulfil these conditions? A recent and rather suitable example within EU are the Netherlands after health care reform in $2006 .^{3}$ However, since the new system has been in progress for just three years, it is too early to draw reliable conclusions within the framework of this paper. As the scope is to look for expenditure development, it is no use surveying time series with substantial system changes. Business areas of PHI and SHI should be staple by and large. Otherwise, time series would depend on each other, comprising misleading information. Therefore, Australia (AUS), Canada (CAN) and Switzerland $(\mathrm{CH})$ are left as appropriate objects. Table 1 gives an overview of health system relevant country data. It shows that the three countries match the proposed model. Country data are juxtaposed to EU(19)-average in order to have a benchmark.

As can be seen, key figures of the three relevant health insurance schemes are

\footnotetext{
${ }^{3}$ See Greß et al. (2007) for a short description.
} 
Table 1: Country figures concerning health system for 2006/2007

\begin{tabular}{|c|c|c|c|c|c|c|c|c|}
\hline \multirow[t]{2}{*}{ Country } & \multicolumn{2}{|c|}{$\%$ Covered } & \multicolumn{3}{|c|}{$\%$ of $\mathrm{TEH}^{a}$} & \multirow{2}{*}{$\begin{array}{c}\% \\
\mathrm{TEH} / \mathrm{GDP}\end{array}$} & \multirow{2}{*}{$\begin{array}{c}\text { Life } \\
\text { Expect. }\end{array}$} & \multirow{2}{*}{$\begin{array}{l}\text { US\$-PPP } \\
\text { GDP/cap }\end{array}$} \\
\hline & SHI & PHI & $\mathrm{SHI}$ & PHI & OOP & & & \\
\hline AUS & 100 & 51.2 & 67.7 & 7.5 & 18.2 & 8.7 & 81.1 & 35952 \\
\hline $\mathrm{CAN}$ & 100 & 67.0 & 70.7 & 12.5 & 14.4 & 10.0 & 80.4 & 36814 \\
\hline $\mathrm{CH}$ & 100 & 27.0 & 59.1 & 9.1 & 30.8 & 11.3 & 81.7 & 38119 \\
\hline $\mathrm{EU}(19)^{b}$ & 97.7 & 26.0 & 76.4 & 6.4 & 13.1 & 9.5 & 79.4 & 29491 \\
\hline
\end{tabular}

Sources: PHIAC (2009), OECD (2009) and BFS (2008)

${ }^{a}$ Missing values to $100 \%$ belong to further financing aggregates, unnecessary within the scope of this paper.

${ }^{b}$ Data in some cases are not as precise and not as up to date as for the other countries due to insufficient availability.

rather similar. Concerning SHI, there is no possibility to opt out of the system, which fixes coverage at 100\%. The Australian and Canadian public health systems are financed almost totally by government. Insurance companies play literally no role for SHI there. However, in Switzerland they are the primary direct financing agents, responsible for about two-thirds of the Swiss public health expenditures. Insurers act as competing non-profit organizations in the regulated SHI market. Nevertheless, expenditures of SHI as a share of TEH are quite in the same range for the three countries. Although SHI coverage is slightly higher, shares of SHI expenditures are in each case lower than for EU(19), whereby this fits in with the presumption of shortened SHI benefits compared to status quo.

PHI coverage differs significantly, ranging from 27.0\% in Switzerland to $67.0 \%$ in Canada. Considering past development, the Canadian figure has gradually increased over time. From 1988 to 2006, PHI expenditure grew more rapidly than OOP expenditure. Private insurance firms increased their share of private expenditures on health from $29.2 \%$ to $40.0 \%$, while the proportion for expenditures OOP dropped from $58.1 \%$ to $48.6 \%$ (CIHI 2008). By contrast, coverage in Switzerland has declined sharply over the last decade, after introducing SHI in 1996. Coverage fell by more than 15 percentage points over the last 15 years. There had been a comparable development in Australia. Right after the statutory health system Medicare was introduced in 1984, PHI coverage dropped by more than $10 \%$ from the mid-1980s to the mid-1990s. Afterwards, governmental counter measuresparticularly subsidies and tax incentives - have brought a trend reversal restoring the pre-1984 level nowadays. Despite these different developments, PHI expenditures as a share of TEH do not differ as much between AUS, CAN and CH. They all exceed the share for EU(19), regardless there are primary and duplicate PHI 
systems responsible for comprehensive benefits in some EU countries. ${ }^{4}$ Remarkably, in each surveyed country payments OOP play a more important role than PHI, leaving virtually much space for market expansion. This is particularly the case for Switzerland.

What are the benefits PHI is responsible for? In Australia, supplementary PHI can cover outpatient services for dental, optical, chiropractical, and psychological treatment as well as inpatient services for private beds in private and public hospitals (Colombo \& Tapay 2003). Swiss private health insurers provide coverage for private beds, parts of dental service, aesthetic surgery, and ambulant nursing (Colombo et al. 2006). Canadians can buy PHI to cover expenses for pharmaceuticals as well as dental, optometrical, psychological, chiropractical, physiotherapeutical, homoeopathical, and home care services (Marchildon 2005; Health Canada 2005). In a nutshell, possible service coverage does not differ much among the three countries. This helps to compare their systems. It is worth mentioning that $\mathrm{PHI}$ is not just responsible for luxury benefits. Actually, there are essential benefits among them, which points out, that private health financing plays an important role in these countries.

\section{Market structure}

This paper does not apply the SCP approach in a very strict manner. Besides the hart figures, soft facts and qualitative information are considered. However, to start with some figures, have a look at Table 2, which gives a snapshot of market concentration. On the one hand, there are a couple of insurers in each of the PHI markets. On the other, markets slightly tend to concentrate and to be dominated, except for CAN. Both in AUS and CH, the leading insurer controls more than onefourth of the market. In both countries a small group of competitors dominates a major share of contracts. Since health insurance is primarily a business on federal state level for each of the countries, there might be stronger market concentrations in some of the states, provinces or cantons, respectively. As Colombo \& Tapay (2003) investigated in an earlier study, some Australian states face regional market shares of the largest competitor up to $70 \% .^{5}$ Anyhow, the figures should not cause worry for two reasons: Firstly, since Kantzenbach (1967) we know that oligopolies can be highly competitive markets if product differentiation is low. Secondly, there is an efficiency trade off in insurance markets concerning market power and risk pooling. Hence, insurance markets are better of being a little concentrated than consisting of insurers too small to diversify risks effectively. Altogether, data in Table 2 show relatively good preconditions for competition.

\footnotetext{
${ }^{4}$ Precisely in Germany, UK, Ireland, Greece, and Portugal (OECD 2009).

${ }^{5}$ Unfortunately there were no federal state level data available for the other countries.
} 
Table 2: Number of competitors and market share for supplementary PHI

\begin{tabular}{|c|c|c|c|}
\hline \multirow[t]{2}{*}{ Country } & \multirow{2}{*}{$\begin{array}{c}\# \text { of } \\
\text { Competitors }\end{array}$} & \multicolumn{2}{|c|}{ Market Share } \\
\hline & & Largest Comp. & 6 Largest Comps. \\
\hline AUS & 38 & $28.7 \%$ & $77.7 \%$ \\
\hline $\mathrm{CAN}$ & 117 & $<15 \%$ & n.a. \\
\hline $\mathrm{CH}$ & 79 & $28.4 \%$ & $68.0 \%$ \\
\hline
\end{tabular}

Sources: PHIAC (2008), CLHIA (2008), OECD (2009) and BPV

(2009)

Despite the three PHI systems are similar in many respects, they vary in crucial details. In order to describe market structure, considerable differences concern profit orientation of insurers, contracting between insurers and insurees, regulation of insurers and products, and incentives to take out coverage.

For-profit organizations dominate the Swiss PHI market. Among them are both independent companies and subsidiaries of the social health insurers. ${ }^{6}$ By contrast, in Australia only 7 out of 38 insurers are for-profit organizations (PHIAC 2009). There is no clear trend for Canada in this regard. However, Canada's PHI market stands out on other grounds: Supplementary PHI coverage usually comes with the job. $97 \%$ of contracts are group-based. They are negotiated and payed by the employer or trade unions (Marchildon 2005). This may explain the high percentage of PHI coverage shown in Table 1. And it may help to strengthen bargaining power to moderate contributions and costs. On the contrary, employment based contracts raise concerns, whether to speak of a voluntary market that enhances individuals freedom of choice. Such a trade off between cost containment and flexibility is not relevant to Australia or Switzerland, where single contracts are predominant.

Concerning governmental influence, PHI regulation is strictest in Australia: Private health insurers have to provide open enrolment, which means that they are not allowed to refuse applicants. Premia have to be community-rated and cannot be adjusted to individual risk (except for a certain loading against age, described below). In order to avoid bad effects of cream skimming and adverse selection under such a scheme, insurance funds belong to a reinsurance pool for financial equalization of different risk structures (Bowie \& Adams 2004). Insurers are free to design new insurance products, but launching and pricing is controlled by Department of Health and Ageing (Colombo \& Tapay 2003). The measure is to provide

${ }^{6}$ Since SHI companies themselves are not allowed to make profit, many of them founded subsidiaries for the supplementary PHI market, where generating profits is permitted. 
freedom of choice and concomitantly to counteract risk segmentation through the back-door by launching products attractive for low risk groups only. Coverage contracts are not temporary, which spares insurees expensive contract prolongation at higher age (and thus, higher risk). Switching the insurer must be possible throughout the year, so as to force competition. All these points of regulation are actually more common to SHI than PHI. This points out the social responsibility, $\mathrm{PHI}$ is meant to assume in Australia. By contrast, none of the mentioned requirements are known to the Canadian or Swiss PHI market. They conduct in a rather unregulated framework which allows them to adjust premia to individual risk and to refuse high risks. While this raises equity concerns (Colombo \& Tapay 2004; OECD 2004), these markets may be more efficient to contain health expenditures. Whether empirical evidence confirms an equality-efficiency trade off will be analyzed later on. So far, one is just able to divide the countries into two groups, the strictly regulated (AUS) and the rather unregulated (CAN \& $\mathrm{CH}$ ).

This finding is correlated to another public influence on the private markets, namely incentives. Incentives to take out supplementary PHI appear in each of the three countries, but their amount and design differ significantly. Australia introduced the most substantial incentives to PHI in order to stop decreasing coverage. Since 1997, the government is subsidizing the system by rebating contributions of persons who take out or already hold PHI. Initially, those subsidies were available only to low and medium income earners. However, since 1999 a $30 \%$ rebate on premia is being provided to all private health insurants. Moreover, Australia implemented an SHI levy surcharge to high income earners, who are not covered by PHI. In 2001, an inducement for people to maintain PHI coverage for entire life was established. This takes the form of a $2 \%$ loading for each year that a person exceeds 30 years of age at the time of joining a PHI fund. However, the maximum loading is capped to 70\% (OECD 2009). Government established this incentive to make PHI attractive for low risks, mediating a better risk pool. In Switzerland there are only some tax deductions for insurees' contributions (Colombo et al. 2006). Canadian provinces offer tax deductibles for employers, buying PHI for their employees. Some provinces also subsidize some private services (Marchildon 2005). But in fact, if one is to build groups by the attribute of public incentives they are not supposed to differ from groups by the attribute regulation. Australian PHI faces considerable incentives, whereas Canadian and Swiss PHI do not as much.

\section{Market conduct}

This section looks at the behavior of market participants within the scope of market structure. It describes direct impacts of certain structures and policy measures. 
A major finding is that despite the relative good preconditions, competition in the surveyed PHI markets is low. In each of the three countries, PHI market consolidates as the number of insurers shrinks. From 2006 to 2007, the Canadian market decreased by nine competitors (CLHIA 2007; 2008). A similar trend can be found for Australia (PHIAC 2009). Consolidation progressed even more sharply in Switzerland, since from 122 insurers in 2004 only 79 are left in 2008. Hefti \& Frey (2008) suppose this trend to go on, which might become a problem in the future.

For present issues, switching of insurers as a key figure for health market competition turns out to be rare. A reason for this might be age reserves for PHI contributions. Usually, younger people taking out PHI pay in the first years of contract much more than they benefit in these years, in order to build age reserves for retirement years when they need more services at lower income. Insurees in high and middle ages face the problem that age reserves cannot be transferred to other insurers, generating high transaction costs of switching. For the special case of Switzerland, switching is additionally hindered by the double role of some insurers in SHI and PHI market. Despite social health insurers have to run their PHI activities in separate business units, separation is often not obvious to customers. Therefore, most of them take out SHI and PHI coverage at the same fund (BFS 2009), which ties them to their private health insurer and lowers switching probability (Beck et al. 2003). Furthermore, customer data collected in SHI may be used for marketing purposes in PHI (Leu et al. 2008). Also, PHI undesirably retroacts to SHI: While medical examination is not allowed in SHI it is a valid tool of risk selection in PHI. Thus, collected data in PHI may help to separate risks in SHI (Paolucci et al. 2007; Hammer et al. 2008; Dormont et al. 2009).

Weak competition is forwarded through insurers, segmenting the market by product differentiation. While this is advertised to enhance consumer choice, the measure intrinsically helps to classify risks. Australian insurers offer differentiated polices to select risks by demand (self-selection), as they are forbidden to refuse applicants. In 2003, there were more than 1600 PHI products available (Colombo \& Tapay 2003). Apparently, the risk structure equalization scheme leaves some gaps for cream skimming, since it is calculated only by age and gender. If people self select by choosing a certain contract, insurers gain an edge of information over the risk equalization scheme. Swiss private health insurers segment their market as well, offering about 2000 different polices in 2008. But the usual way to select risks in unregulated markets is to examine the applicants' health before contracting. Canadian and Swiss insurers are bound to apply this expensive method, as they find themselves in a prisoners' dilemma, raising administrative costs in order to avoid adverse selection. If some would not examine applicants, but some of them do, the former would attract all the bad risks, leading to higher expenses and thus to higher contributions, making themselves unattractive to better risks. Therefore, 
insurers in the unregulated markets rather compete by selecting good risks than offering better service or being more efficient in administration. Since there is open enrolment and community rating in Australia, health tests are not applied there. However, the Australian scheme bears other problems leading to adverse selection as well. While supplementary PHI is not mandatory but community rated, low risks find themselves better off opting out of coverage and paying on demand, leaving a pool with higher average risk behind (Paolucci et al. 2008). The problem occurs (to a lesser extend) to the other countries as well, since their PHI markets face information asymmetries between applicants and funds too. ${ }^{7}$

As stated at the beginning of this paper, broadening the field for supplementary PHI is supposed to enable selective contracting between insurers and health service providers. Private health insurers are allowed to negotiate service prices and refuse expensive or low-quality providers (Newhouse 1982). In comparison to simple reimbursement schemes, the measure should enforce quality and price competition of providers. Moreover, the active role of insurers is supposed to constrain over-utilization of health resources by customers. In fact, none of the surveyed PHI markets applies selective contracting or other measures of managed care, although they are permitted to. All funds serve as passive indemnity insurers. There may be at least three causes to that - two are supply-driven, the third one is demand-driven. Each group of stakeholders (insurers, providers, insurees) is involved: Firstly, insurers business area could be too small. That does not allow for high expenditures to benchmark quality, own investments to improve quality and bilateral negotiations (OECD 2004). Secondly, providers might refuse to negotiate prices on a bilateral level, as this would weaken their position, while augmenting their administrative effort (Nichols et al. 2004). Thirdly, customers demand supplementary PHI in order to enhance their freedom of choice and not to be restricted by their insurer. Hence, funds avoid offering restricted contracts.

Whatever the reasons might be, empirical evidence in this survey refutes two central reasonings to widen PHI responsiveness: Insurers do not play an active role in health service management as they do not employ managed care mechanisms. Moreover, funds do not compete as supposed to, since switching is low and cream skimming is in place. Hence, quality improvements and cost efficiency can not be

\footnotetext{
${ }^{7}$ Therefore, adverse selection is one factor to explain the idle market space for PHI displayed in Table 1 by the high share of OOP payments vs. PHI expenditures. Another factor might be that many people cannot effort PHI and thus have to pay OOP when it comes to injury uncovered by SHI. In Canada, where PHI coverage is primarily employment linked, coverage underlies further obstacles, e.g. for the unemployed. Moreover, there are some business areas, such as co-payments, PHI must not cover and there might be some unprofitable business areas, insurers eschew to cover. Historical reasons may matter as well, since e.g. Swiss people have only been covered by a SHI since 1996. Financing health expenditures OOP is familiar to them.
} 
expected from widening the field for PHI. The next section deals with measuring these expectations.

\section{Market performance}

This section looks at outcomes of competition concerning cost development and quality of service. To start with some pecuniary factors, see Figures 1 and 2. For each of the three countries, these figures compare expenditures of PHI vs. SHI. While Figure 1 displays TEH per insuree against time in order to express the development of contributions (or public expenses under a tax financed scheme), Figure 2 displays management expenses per insuree against time in order to express cost efficiency. ${ }^{8}$ The left column of charts in each figure contains nominal costs. They are included as additional information to get a picture of the cost levels. However, it would be no use to draw comparison on these nominal grounds, as they are level-dependent. For TEH per insuree, SHI has a much higher level, since it covers more benefits. For management expenditures per insuree, PHI has a higher level, since there are additional expenditures for advertising etc., SHI may not face. This is why the right column of charts abstracts from levels and displays the development as an index with a basic year in order to make time series comparable. In fact this means, the figures compare cost developments, more precisely, accumulated growth rates of total expenditures and management expenditures of SHI and PHI for the longest available time series.

Concerning TEH, these data can not provide information about which one is cheaper in covering certain services, since these are just trends, and since PHI and SHI - by definition - do not have any covered services in common. But they are an indicator for what would have been the total costs, if any randomly chosen marginal service unit, currently covered by SHI, would have been covered by PHI, and vice versa. ${ }^{9}$ Administrative task areas of SHI and PHI are not as discret as covered benefits. In fact they coincide in several respects. Moreover, the levels of ME per insuree are pretty much the same. Hence, these series show, which one developed more efficiently in recent years.

What are the major findings of the comparison? Concerning TEH per insuree, PHI and SHI shape up with a slower growth for SHI in two of three countries, and rather similar for the third. The indexed time series have been tested for

\footnotetext{
${ }^{8}$ Unfortunately, data could not be collected for the same period of time for each country. The figures display the longest continuously available time series. Within these years, responsiveness for benefits did not change substantial in the three countries.

${ }^{9}$ The dichotomy of benefits covered by SHI and PHI is actually advantageous, as data are not biased by cross-subsidizing from PHI patients to SHI patients, which in fact occurs in systems with primary or duplicate PHI.
} 

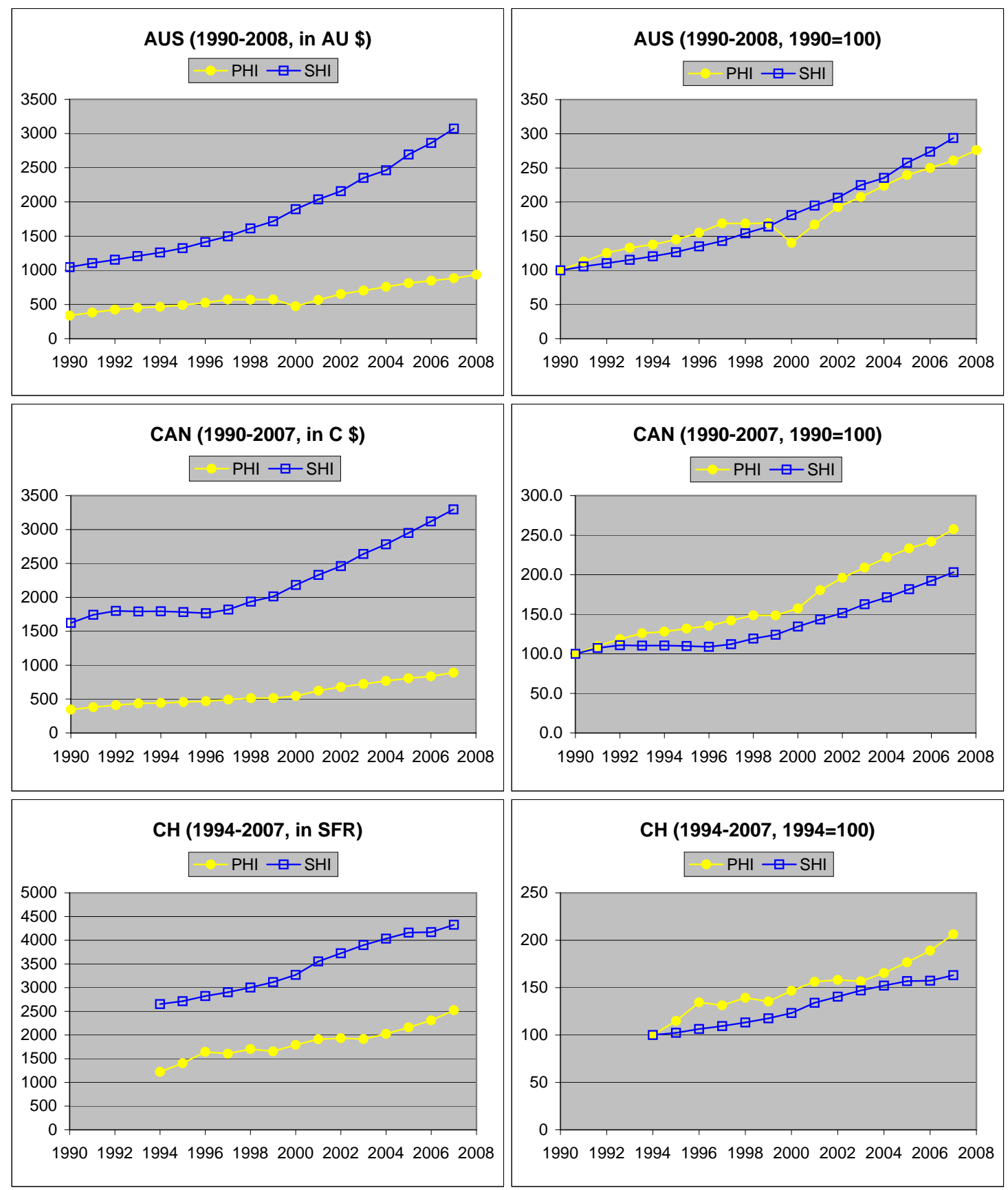

Sources: OECD (2009), PHIAC (2009), AIHW (2009), CIHI (2008), BAG (2009), BFS (2004; 2009).

Figure 1: Total expenditures on health per insuree and year 

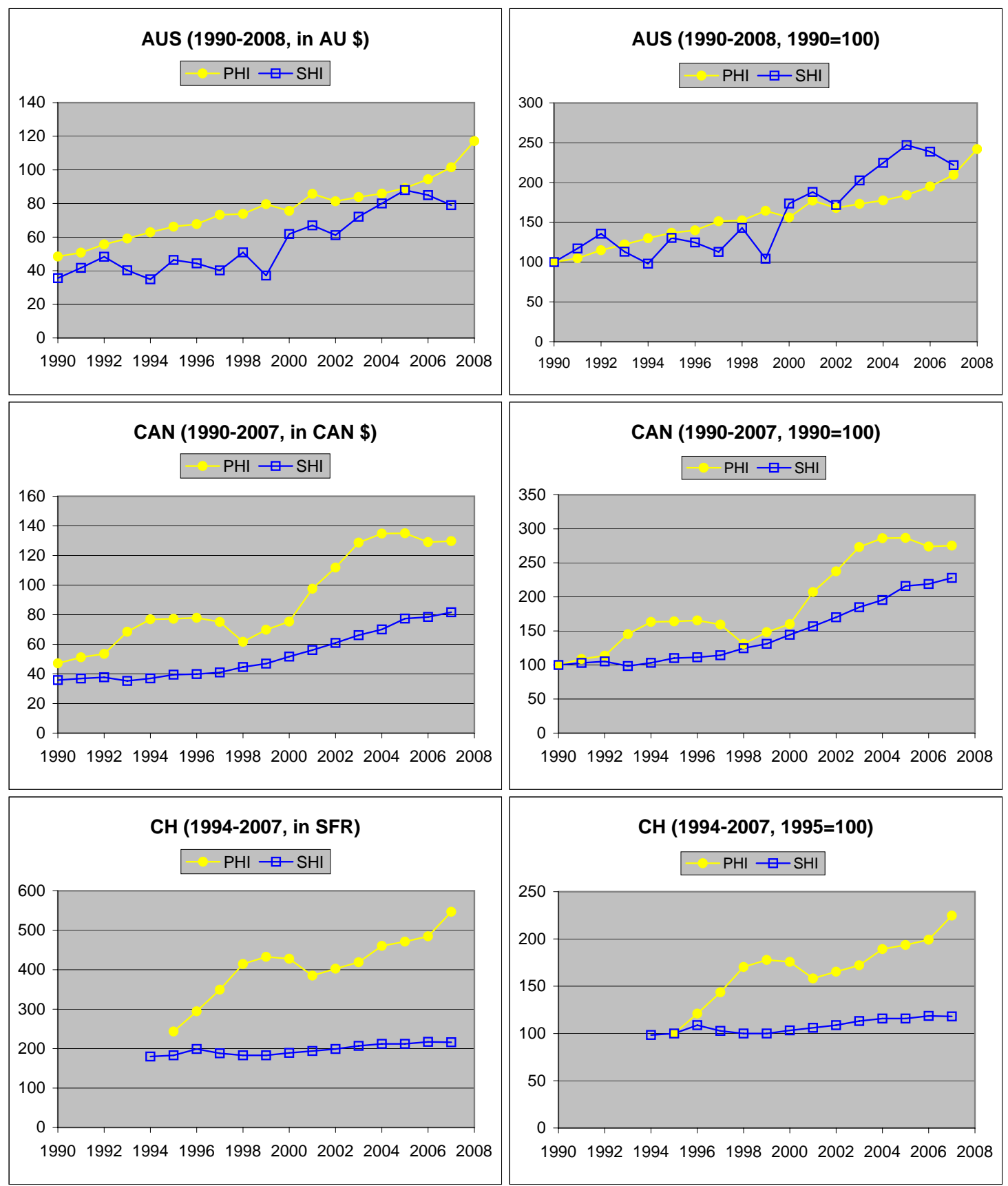

Sources: OECD (2009), PHIAC (2009), AIHW (2009), CIHI (2008), BAG (2009), BFS (2004; 2009).

Figure 2: Management expenses per insuree and year 
equality of means. ${ }^{10}$ Means are significantly higher for PHI than SHI in Canada and Switzerland. The tests reject equality on a 5\% level. For Australia, means of TEH per insuree show no significant difference. TEH grow faster for PHI before the considerable break in the time series and grow slower afterwards. Responsiveness of services did not change significantly over the considered period. Thus, it must have been prices that grew at a faster rate for PHI than for SHI. One might put these changes in relative prices down to changes in relative costs for the basket of services covered by PHI to those covered by SHI. Hence, one would doubt comparability of cost effectiveness along these figures. But this is only half the truth, since introducing PHI was meant to contain costs of services, which particularly includes negotiating moderate prices. Thus, as far as private health insurers perform worse than SHI in containing the price of any randomly chosen marginal benefit unit, shrinking the latter in favor of the former does not pay off from an expenditure point of view. Similar studies (Mossialos \& Thomson 2002a; Greß 2005) confirm these empirical findings for some European countries with different roles for PHI in their health system. Additionally, they find quality of service to be better enhanced by bargaining power of SHI.

Results are more distinct for management expenditures. As shown in Figure 2, administrative costs per insuree for PHI develop worse compared to SHI in two of three countries (CAN \& CH) and develop similar in the third (AUS). Statistical tests verify these first impressions, since means differ significantly on a $5 \%$ level for CAN and CH, and do not for AUS. CIHI (2008) and (Mossialos \& Thomson 2002b) announced analogous results for Canada and some European Countries. Economic theory considers high transaction costs to be inefficient if they can be avoided under an alternative system of funding and providing health care (Barr 1992). Thus, empirical evidence does not support expansion of PHI, but rather repelling it.

Australia plays a special role among the surveyed countries. It is the only country where PHI can compete with SHI concerning development of TEH and ME per insuree in recent years. Concurrently, Australia applies the strictest regulation, the largest public impact to take out PHI, and the lowest share of profit-oriented insurers. In a nutshell, it has the PHI scheme with the highest affinity to an SHI scheme. As insurers do not use health tests, they are able to release management expenses. In general, funds save costs for risk selection in comparison to the other countries. Thus, there is no regulation-efficiency trade off. At the same time, Australia stresses equality in PHI coverage like no other surveyed country (Colombo \& Tapay 2003, 2004; OECD 2004). Taking this into account, empirical evidence shows no equality-efficiency trade off between unregulated and regulated PHI markets. Both aims are better met by regulated schemes.

\footnotetext{
${ }^{10}$ See the statistical appendix for details of the tests.
} 
If one is to look at the Australian chart in Figure 1 again, the break in the time series around 1999 attracts attention. It causes PHI to grow slower than SHI concerning TEH per insuree in subsequent years. The break is due to several measures at the end of the 1990s to encourage demand for PHI. Before these interventions, coverage fell rapidly and the PHI market was likely to break down by reason of adverse selection. As incentives worked and coverage grew fast, adverse selection could be curtailed and thus, contributions per insuree could fall. Hence, the rather good performance of Australian PHI is largely put down to subsidies and tax incentives. Maybe public expenses were lower, if supplementary services were covered by SHI, saving subsidies and costs of regulation. ${ }^{11}$ The question, if subsidies are worth it, should be looked at in more detail in future research.

\section{Conclusions}

The paper aimed to test the widespread opinion that shrinking benefits of SHI in favor of PHI is likely to enable a rational use of health resources and to maintain affordable health expenditures. Thus, it surveyed health systems that promote a distinct role for PHI and strictly separate responsibilities between PHI and SHI, assigning SHI the role of a basic insurance and PHI the role of a supplementary insurance. Empirical evidence derives from the health insurance schemes of Australia, Canada and Switzerland that permit voluntary supplementary insurance in a regime with a mandatory basic insurance package. Coverable benefits do not differ very much, which makes the systems comparable.

Although market structures provide relatively good grounds for competition, markets conduct and perform not in the desired way. Insurers do not compete by quality or cost effectiveness, as they lack power to curtail costs of service and lack the incentive to utilize selective contracting or other measures of managed care. Since private health insurers in fact do not apply methods of active care management in any of the surveyed countries, no quality improvements or cost containments can be expected. Far from it, insurers find themselves in a prisoners' dilemma. They bear high expenses to select risks by health tests and product differentiation in order to avoid adverse selection against their competitors.

These findings come along with weak market performance in recent years, as total expenditures on health and management expenditures (both per insuree) grow

\footnotetext{
${ }^{11}$ Besides preventing the supplementary PHI market to break down, subsidies had another aim: They should lower expenditures on public hospitalization, by shifting demand to the private sector, as PHI covers private hospitalization (Walker et al. 2007). However, this did not come true. While the measure can be called effective in supporting PHI in this scheme, it failed to lower the utilization of public services and therefore unburden the public budget.(Paolucci et al. 2008) In fact subsidies generated, rather than merely shifted, demand for health (Moorin \& Holman 2006). Therefore, subsidies might cause higher costs than they save.
} 
faster in comparison to SHI in two of the three countries. Thus, assuming any randomly chosen marginal benefit unit, currently covered by SHI, to have been covered by PHI in these years would have led to higher total health costs. Hence, shrinking benefits of SHI in favor of PHI seems not to be a measure to improve cost efficiency. Comparing management expenditures yields similar results. Since they grow faster for PHI accruing from a higher level, they do not support introduction of PHI by reasons of cost containment. Only the health system of Australia, where accumulated growth rates of PHI expenditures keep up with those of SHI, stands out from these findings. However, private insurance contracts are strictly regulated and intensively subsidized there, whereby PHI resembles SHI, stressing the importance of equality in the Australian PHI market. Unregulated PHI markets on the other hand lack equality, but do not yield better cost containment. Thus, there seems to be no trade off between equality and efficiency, making no good case for introducing lowly regulated PHI markets.

As either PHI performs worse than SHI or it has to be strictly regulated and subsidized by government, it is questionable whether introducing or forcing supplementary PHI is a useful measure to contain TEH. Shifting responsiveness from public to private sector in order to lower public expenditures, requires high subsidies that might even exceed the savings. If equal access to services and high coverage of certain services are health policy aims, it seems to be more effective to have them covered by SHI. If high coverage is not that favored, supplementary PHI might be a solution, but regulation has to be strict to promote equality and effectiveness. Experience from Australia shows that adverse selection can be defeated by moderate incentives to take out PHI.

To sum up, the two points listed in the first section can now be evaluated:

1. Free markets for supplementary PHI in this survey do not comply with intense competition - neither amongst insurers nor health service providers. They do not enforce higher quality or lower growth of costs, but risk selection. SHI schemes have performed better concerning costs over the last years. Only regulated PHI schemes could keep up with SHI. Additionally, SHI and regulated PHI guarantee more equality than unregulated PHI schemes.

2. Reducing benefits of SHI and widening the field of PHI has to be accommodated by subsidies and might not shift, but only generate further demand for health services. Therefore, public cost containment is at least questionable. Further research is needed at this point.

Empirical evidence shows the obstacles of introducing PHI in practice and cautions policy makers about setting effective regulation and moderate incentives. 


\section{References}

Australian Institute of Health and Welfare (AIHW) (2009). Expenditure data cubes. http://www.aihw.gov.au/expenditure/datacubes/index. cfm.

BARR, N. (1992). Economic theory and the welfare state: a survey and interpretation. Journal of Economic Literature, 30(2), 741-803.

Beck, K., S. H. A. Spycher, \& L. Gardiol (2003). Risk adjustment in Switzerland. Health Policy, 65(1), 63-74.

Bowie, R. \& G. Adams (2004). Financial and management practice in a voluntary medical insurance company in the developed world: Background Paper for Conference on Private Health Insurance in Developing Countries. Conference Paper, Wharton Business School.

Bundesamt Für Gesundheit (BAG) (2009). Statistik der obligatorischen Krankenversicherung. http://www.bag.admin.ch/themen/ krankenversicherung/01156/02446/index.html?lang=de.

Bundesamt FÜr Privatversicherungen (BPV) (2009). Stocks of risks and contracts. http://www.finma.ch/archiv/bpv/d/dokumentation/00439/ 01389/01393/01404/01435/index.html?lang=de.

Bundesamt FÜR Statistik (BFS) (2004). Schweizerische Gesundheitsbefragung 2002. Press release 0350-0404-60, Neuchâtel.

Bundesamt FÜR Statistik (BFS) (2008). Kosten und Finanzierung des Gesundheitswesens: Detaillierte Ergebnisse 2006 und jüngste Entwicklung. Statistik der Schweiz. BFS, Neuchâtel.

Bundesamt FÜR Statistik (BFS) (2009). Schweizerische Gesundheitsbefragung 2007. Survey, Neuchâtel.

Canadian Institute for Health Information (CIHI) (2008). National Health Expenditure Trends, 1975-2008. CIHI, Ottawa.

Canadian Life and Health Insurance Association (ClHiA) (2007). Canadian Life and Health Insurance Facts: 2006 edition.

Canadian life and Health Insurance Association (ClHiA) (2008). Key Statistics: 2008 Edition. http://www.clhia.ca/download/KeyStats2008_EN. pdf. 
Colombo, F. \& N. TAPAy (2003). Private Health Insurance in Australia: A case study. OECD Health Working Papers 8, Paris.

Colombo, F. \& N. TAPAY (2004). Private Health Insurance in OECD Countries: The Benefits and Costs for Individuals and Health Systems. OECD Health Working Papers 15, Paris.

Colombo, F., P. Zurn, \& H. Oxley (2006). Switzerland, OECD reviews of health systems, vol. 25. OECD, Paris.

Cutler, D. M., M. McClellan, \& J. P. Newhouse (2000). How does managed care do it? RAND Journal of Economics, 31(3), 526-548.

Dormont, B., P.-Y. Geoffard, \& K. Lamiraud (2009). The influence of supplementary health insurance on switching behaviour: evidence from Swiss data. Health Economics, 18(published online).

European Commission (2005). Review of Preliminary National Policy Statements on Health Care and Long-term Care. Memorandum of the Social Protection Committee, Brussels.

European Commission (2008). Review of the Long-term care part of the National Reports on Strategies for Social Protection and Social Inclusion 2006-2008 and updates 2007. Tech. rep., Brussels.

Glied, S. (2000). Managed care. In A. J. Culyer \& J. P. Newhouse (eds.), Handbook of health economics, vol. 1, pp. 707-753. Elsevier, Amsterdam.

Goldman, D. P. (1995). Managed Care as a Public Cost-Containment Mechanism. RAND Journal of Economics, 26(2), 277-295.

Gress, S. (2005). The Role of Private Health Insurance in Social Health Insurance Countries: Implications for Canada. In C. M. Flood, K. Roach, \& L. Sossin (eds.), Access to care - access to justice: The legal debate over private health insurance in Canada, pp. 278-295. University of Toronto Press, Toronto.

Gress, S. (2006). Regulated Competition in Social Health Insurance: A ThreeCountry Comparison. International Social Security Review, 59(3), 27-47.

Gress, S., M. Manouguian, \& J. Wasem (2007). Health Insurance Reform in the Netherlands. CESifo DICE-Report - Journal for Institutional Comparisons, $5(1), 63-67$. 
Hammer, S., M. Peter, \& J. Trageser (2008). Wettbewerb im Gesundheitswesen: Auslegeordnung: Schlussbericht. Forschungsprotokoll 9, Obsan, Neuchâtel.

Health Canada (2005). Canada's health care system. Health Canada, Ottawa.

Hefti, C. \& M. Frey (2008). Die Entwicklung der Versicherungslandschaft in der Krankenversicherung 1996-2006: Schlussbericht. Forschungsprotokoll 8, Obsan, Neuchâtel.

Kantzenbach, E. (1967). Die Funktionsfähigkeit des Wettbewerbs. 2nd ed. Vandenhoeck \& Ruprecht, Göttingen.

Leu, R. E., F. F. H. Rutten, W. Brouwer, C. Rütschi, \& P. Matter (2008). The Swiss and the Dutch health care systems compared: A tale of two systems, Gesundheitsökonomische Beiträge, vol. 53. Nomos, Baden-Baden.

Marchildon, G. P. (2005). Health Systems in Transition: Canada. Tech. rep., European Observatory on Health Systems and Policies, Copenhagen.

Mays, G. P., G. Claxton, \& J. White (2004). Managed Care Rebound? Recent Changes In Health Plans' Cost Containment Strategies. Health Affairs, 23(2), 427-437.

Moorin, R. E. \& C. D. J. Holman (2006). Does federal health care policy influence switching between the public and private sectors in individuals? Health Policy, 79(2-3), 284-295.

Mossialos, E. \& S. Thomson (2002a). Voluntary Health Insurance in the European Union: a critical assessment. International Journal of Health Services, 32(1), 19-88.

Mossialos, E. \& S. Thomson (2002b). Voluntary health insurance in the European Union: Report prepared for the Directorate General for Employment and Social Affairs of the European Commission. http://ec.europa.eu/ employment_social/spsi/docs/social_protection/vhi_en.pdf.

Newhouse, J. P. (1982). Is competition the answer? Journal of Health Economics, 1(1), 109-116.

Nichols, L. M., P. B. Ginsburg, R. A. Berenson, J. Christianson, \& R. E. Hurley (2004). Are market forces strong enough to deliver efficient health care systems? Confidence is waning. Health Affairs, 23(2), 8-21. 
OECD (2004). Private health insurance in OECD countries: The OECD health project. OECD, Paris.

OECD (2009). Health Data 2009. http://www. oecd.org/health/healthdata.

Paolucci, F., J. R. G. Butler, \& W. P. M. M. de van Ven (2008). Subsidising private health insurance in Australia: Why, how, and how to proceed? ACERH working paper 2, Canberra.

Paolucci, F., E. Schut, K. Beck, S. Gress, C. De van Voorde, \& I. Zmora (2007). Supplementary health insurance as a tool for risk-selection in mandatory basic health insurance markets. Health Economics, Policy and Law, 2(2), 173192.

Pati, S., S. Shea, D. Rabinowitz, \& O. Carrasquillo (2005). Health Expenditures for Privately Insured Adults Enrolled in Managed Care Gatekeeping vs Indemnity Plans. American Journal of Public Health, 95(2), 286-291.

Private Health Insurance Administration Council (PHiAC) (2008). Operations of the Private Health Insurers. Annual Report 2007-08, Canberra.

Private Health Insurance Administration Council (PHiAC) (2009). Industry Statistics. http://www.phiac.gov.au/statistics/trends/index. htm.

SCHERER, F. M. \& D. Ross (1990). Industrial market structure and economic performance. 3rd ed. Houghton Mifflin, Boston, Mass.

Tuohy, C. H., C. M. Flood, \& M. Stabile (2004). How does private finance affect public health care systems? Marshaling the evidence from OECD nations. Journal of Health Politics, Policy and Law, 29(3), 359-396.

Walker, A. E., R. Percival, L. Thurecht, \& J. Pearse (2007). Public policy and private health insurance: distributional impact on public and private hospital usage. Australian Health Review, 31(2), 305-314. 


\section{Statistical Appendix}

The following list shows statistical tests concerning equality of means of the indexed time series (right columns of Figures 1 and 2). Significant $p$-values $(p<0.05)$ indicate considerable differences between two time series, respectively. Data were tested and put out with the statistical software R.

Welch Two Sample t-test

data: meantest\$TEH_AUS_PHI and meantest\$TEH_AUS_SHI

$\mathrm{t}=0.1603, \mathrm{df}=33.323, \mathrm{p}$-value $=0.8736$

alternative hypothesis: true difference in means is not equal to 0

95 percent confidence interval:

$-35.3045141 .34545$

sample estimates:

mean of $\mathrm{x}$ mean of $\mathrm{y}$

$177.6316 \quad 174.6111$

\section{Welch Two Sample t-test}

data: meantest\$TEH_CAN_PHI and meantest\$TEH_CAN_SHI

$t=2.1257, \mathrm{df}=29.765, \mathrm{p}$-value $=0.04194$

alternative hypothesis: true difference in means is not equal to 0

95 percent confidence interval:

1.15220758 .070015

sample estimates:

mean of $\mathrm{x}$ mean of $\mathrm{y}$

$166.0000 \quad 136.3889$

\section{Welch Two Sample t-test}

data: meantest\$TEH_CH_PHI and meantest\$TEH_CH_SHI

$t=2.1297, \mathrm{df}=24.738, \mathrm{p}$-value $=0.04334$

alternative hypothesis: true difference in means is not equal to 0

95 percent confidence interval:

0.668965940 .6167484

sample estimates:

mean of $\mathrm{x}$ mean of $\mathrm{y}$

$150.7143 \quad 130.0714$ 
data: meantest\$ME_AUS_PHI and meantest $\$ M E_{-}$AUS_SHI

$t=-0.0333, \mathrm{df}=30.544, \mathrm{p}$-value $=0.9737$

alternative hypothesis: true difference in means is not equal to 0 95 percent confidence interval:

$-30.45222 \quad 29.47561$

sample estimates:

mean of $\mathrm{x}$ mean of $\mathrm{y}$

$157.7895 \quad 158.2778$

\section{Welch Two Sample t-test}

data: meantest\$ME_CAN_PHI and meantest $\$ M E \_C A N \_S H I$

$t=2.3002, \mathrm{df}=30.292, \mathrm{p}$-value $=0.02850$

alternative hypothesis: true difference in means is not equal to 0

95 percent confidence interval:

4.89364782 .106353

sample estimates:

mean of $\mathrm{x}$ mean of $\mathrm{y}$

188.7222145 .2222

Welch Two Sample t-test

data: meantest\$ME_CH_PHI and meantest $\$ M E \_C H \_S H I$

$\mathrm{t}=6.4886, \mathrm{df}=13.14, \mathrm{p}$-value $=1.938 \mathrm{e}-05$

alternative hypothesis: true difference in means is not equal to 0

95 percent confidence interval:

40.4992780 .86337

sample estimates:

mean of $\mathrm{x}$ mean of $\mathrm{y}$

168.5385107 .8571 


\section{CESifo Working Paper Series}

for full list see www.cesifo-group.org/wp

(address: Poschingerstr. 5, 81679 Munich, Germany, office@cesifo.de)

2677 Rolf Golombek and Michael Hoel, International Cooperation on Climate-Friendly Technologies, June 2009

2678 Martin Cave and Matthew Corkery, Regulation and Barriers to Trade in Telecommunications Services in the European Union, June 2009

2679 Costas Arkolakis, A Unified Theory of Firm Selection and Growth, June 2009

2680 Michelle R. Garfinkel, Stergios Skaperdas and Constantinos Syropoulos, International Trade and Transnational Insecurity: How Comparative Advantage and Power are Jointly Determined, June 2009

2681 Marcelo Resende, Capital Structure and Regulation in U.S. Local Telephony: An Exploratory Econometric Study; June 2009

2682 Marc Gronwald and Janina Ketterer, Evaluating Emission Trading as a Policy Tool Evidence from Conditional Jump Models, June 2009

2683 Stephan O. Hornig, Horst Rottmann and Rüdiger Wapler, Information Asymmetry, Education Signals and the Case of Ethnic and Native Germans, June 2009

2684 Benoit Dostie and Rajshri Jayaraman, The Effect of Adversity on Process Innovations and Managerial Incentives, June 2009

2685 Peter Egger, Christian Keuschnigg and Hannes Winner, Incorporation and Taxation: Theory and Firm-level Evidence, June 2009

2686 Chrysovalantou Milliou and Emmanuel Petrakis, Timing of Technology Adoption and Product Market Competition, June 2009

2687 Hans Degryse, Frank de Jong and Jérémie Lefebvre, An Empirical Analysis of Legal Insider Trading in the Netherlands, June 2009

2688 Subhasish M. Chowdhury, Dan Kovenock and Roman M. Sheremeta, An Experimental Investigation of Colonel Blotto Games, June 2009

2689 Alexander Chudik, M. Hashem Pesaran and Elisa Tosetti, Weak and Strong Cross Section Dependence and Estimation of Large Panels, June 2009

2690 Mohamed El Hedi Arouri and Christophe Rault, On the Influence of Oil Prices on Stock Markets: Evidence from Panel Analysis in GCC Countries, June 2009

2691 Lars P. Feld and Christoph A. Schaltegger, Political Stability and Fiscal Policy - Time Series Evidence for the Swiss Federal Level since 1849, June 2009 
2692 Michael Funke and Marc Gronwald, A Convex Hull Approach to Counterfactual Analysis of Trade Openness and Growth, June 2009

2693 Patricia Funk and Christina Gathmann, Does Direct Democracy Reduce the Size of Government? New Evidence from Historical Data, 1890-2000, June 2009

2694 Kirsten Wandschneider and Nikolaus Wolf, Shooting on a Moving Target: Explaining European Bank Rates during the Interwar Period, June 2009

2695 J. Atsu Amegashie, Third-Party Intervention in Conflicts and the Indirect Samaritan's Dilemma, June 2009

2696 Enrico Spolaore and Romain Wacziarg, War and Relatedness, June 2009

2697 Steven Brakman, Charles van Marrewijk and Arjen van Witteloostuijn, Market Liberalization in the European Natural Gas Market - the Importance of Capacity Constraints and Efficiency Differences, July 2009

2698 Huifang Tian, John Whalley and Yuezhou Cai, Trade Sanctions, Financial Transfers and BRIC's Participation in Global Climate Change Negotiations, July 2009

2699 Axel Dreher and Justina A. V. Fischer, Government Decentralization as a Disincentive for Transnational Terror? An Empirical Analysis, July 2009

2700 Balázs Égert, Tomasz Koźluk and Douglas Sutherland, Infrastructure and Growth: Empirical Evidence, July 2009

2701 Felix Bierbrauer, Optimal Income Taxation and Public Goods Provision in a Large Economy with Aggregate Uncertainty, July 2009

2702 Marc Gronwald, Investigating the U.S. Oil-Macroeconomy Nexus using Rolling Impulse Responses, July 2009

2703 Ali Bayar and Bram Smeets, Government Deficits in the European Union: An Analysis of Entry and Exit Dynamics, July 2009

2704 Stergios Skaperdas, The Costs of Organized Violence: A Review of the Evidence, July 2009

2705 António Afonso and Christophe Rault, Spend-and-tax: A Panel Data Investigation for the EU, July 2009

2706 Bruno S. Frey, Punishment - and beyond, July 2009

2707 Michael Melvin and Mark P. Taylor, The Crisis in the Foreign Exchange Market, July 2009

2708 Firouz Gahvari, Friedman Rule in a Model with Endogenous Growth and Cash-inadvance Constraint, July 2009 
2709 Jon H. Fiva and Gisle James Natvik, Do Re-election Probabilities Influence Public Investment?, July 2009

2710 Jarko Fidrmuc and Iikka Korhonen, The Impact of the Global Financial Crisis on Business Cycles in Asian Emerging Economies, July 2009

2711 J. Atsu Amegashie, Incomplete Property Rights and Overinvestment, July 2009

2712 Frank R. Lichtenberg, Response to Baker and Fugh-Berman's Critique of my Paper, "Why has Longevity Increased more in some States than in others?", July 2009

2713 Hans Jarle Kind, Tore Nilssen and Lars Sørgard, Business Models for Media Firms: Does Competition Matter for how they Raise Revenue?, July 2009

2714 Beatrix Brügger, Rafael Lalive and Josef Zweimüller, Does Culture Affect Unemployment? Evidence from the Röstigraben, July 2009

2715 Oliver Falck, Michael Fritsch and Stephan Heblich, Bohemians, Human Capital, and Regional Economic Growth, July 2009

2716 Wladimir Raymond, Pierre Mohnen, Franz Palm and Sybrand Schim van der Loeff, Innovative Sales, R\&D and Total Innovation Expenditures: Panel Evidence on their Dynamics, July 2009

2717 Ben J. Heijdra and Jochen O. Mierau, Annuity Market Imperfection, Retirement and Economic Growth, July 2009

2718 Kai Carstensen, Oliver Hülsewig and Timo Wollmershäuser, Price Dispersion in the Euro Area: The Case of a Symmetric Oil Price Shock, July 2009

2719 Katri Kosonen and Gaëtan Nicodème, The Role of Fiscal Instruments in Environmental Policy, July 2009

2720 Guglielmo Maria Caporale, Luca Onorante and Paolo Paesani, Inflation and Inflation Uncertainty in the Euro Area, July 2009

2721 Thushyanthan Baskaran and Lars P. Feld, Fiscal Decentralization and Economic Growth in OECD Countries: Is there a Relationship?, July 2009

2722 Nadia Fiorino and Roberto Ricciuti, Interest Groups and Government Spending in Italy, 1876-1913, July 2009

2723 Andreas Wagener, Tax Competition, Relative Performance and Policy Imitation, July 2009

2724 Hans Fehr and Fabian Kindermann, Pension Funding and Individual Accounts in Economies with Life-cyclers and Myopes, July 2009

2725 Ernesto Reuben and Arno Riedl, Enforcement of Contribution Norms in Public Good Games with Heterogeneous Populations, July 2009 
2726 Kurt Schmidheiny and Marius Brülhart, On the Equivalence of Location Choice Models: Conditional Logit, Nested Logit and Poisson, July 2009

2727 Bruno S. Frey, A Multiplicity of Approaches to Institutional Analysis. Applications to the Government and the Arts, July 2009

2728 Giovanni Villani, A Strategic R\&D Investment with Flexible Development Time in Real Option Game Analysis, July 2009

2729 Luca Di Corato and Michele Moretto, Investing in Biogas: Timing, Technological Choice and the Value of Flexibility from Inputs Mix, July 2009

2730 Gilad D. Aharonovitz, Nathan Skuza and Faysal Fahs, Can Integrity Replace Institutions? Theory and Evidence, July 2009

2731 Michele Moretto and Sergio Vergalli, Managing Migration through Conflicting Policies: an Option-theory Perspective, July 2009

2732 Volker Nitsch, Fly or Cry: Is Airport Noise Costly?, July 2009

2733 Francesco Cinnirella and Joachim Winter, Size Matters! Body Height and Labor Market Discrimination: A Cross-European Analysis, July 2009

2734 Samuel Bowles and Sandra Polanía Reyes, Economic Incentives and Social Preferences: A Preference-based Lucas Critique of Public Policy, July 2009

2735 Gary Burtless, Lessons of the Financial Crisis for the Design of National Pension Systems, July 2009

2736 Helmuth Cremer, Firouz Gahvari and Pierre Pestieau, Fertility, Human Capital Accumulation, and the Pension System, July 2009

2737 Hans Jarle Kind and Frank Stähler, Market Shares in Two-Sided Media Industries, July 2009

2738 Pamela Campa, Alessandra Casarico and Paola Profeta, Gender Culture and Gender Gap in Employment, August 2009

2739 Sebastian Gechert, Supplementary Private Health Insurance in Selected Countries: Lessons for EU Governments?, August 2009 